\title{
Atividade do herbicida acetochlor em solo submetido à semeadura direta e ao preparo convencional ${ }^{(1)}$
}

\author{
Miguel Vicente Weiss Ferri(2), Ribas Antonio Vidal(3), Juliana Gomes ${ }^{(4)}$, \\ Deborah Pinheiro Dick ${ }^{(5)}$ e Roberto Fernando de Souza(5)
}

\begin{abstract}
Resumo - Com o objetivo de estudar a atividade do herbicida acetochlor em Argissolo Vermelho submetido à semeadura direta e ao preparo convencional, foram conduzidos experimentos no campo e em laboratório. $\mathrm{O}$ herbicida apresentou menor controle das plantas daninhas na semeadura direta do que sob preparo convencional. A redução de matéria seca de trigo na amostra de solo coletada na profundidade de 16-19 cm foi superior sob semeadura direta, indicando maior potencial de lixiviação do herbicida neste sistema de preparo. Os valores de coeficiente de partição do herbicida no solo $\left(\mathrm{K}_{\mathrm{d}}\right)$ foram de 2,75 e 1,67 L kg-1 em relação ao solo sob semeadura direta e preparo convencional, respectivamente, indicando que o primeiro apresentou maior capacidade de sorver acetochlor. O coeficiente de partição em relação ao teor de carbono orgânico $\left(\mathrm{K}_{\mathrm{oc}}\right)$ foi de 166 e $126 \mathrm{~L} \mathrm{~kg}^{-1}$ no solo cultivado em semeadura direta e sob preparo convencional, respectivamente, sugerindo que o herbicida foi sorvido em maior intensidade pela matéria orgânica do solo sob semeadura direta.
\end{abstract}

Termos para indexação: planta daninha, manejo do solo, sorção, lixiviação do solo.

\section{Activity of the herbicide acetochlor in soil under no-till and conventional tillage systems}

\begin{abstract}
The activity of herbicide acetochlor in a Red Argisol (Paleudult) under no-till and conventional tillage systems was investigated in laboratory and field experiments. The herbicide was less efficient on weed control under no-till system than under conventional tillage. The reduction of wheat dry matter, evaluated in the sample collected from the $16-19 \mathrm{~cm}$ depth, was higher under no-till, suggesting a greater leaching capacity in this soil tillage system. The acetochlor sorption was higher on no-till system than in the conventional tillage, as indicated by the distribution coefficients on soil $\left(\mathrm{K}_{\mathrm{d}}\right)$ : 2.75 and $1.67 \mathrm{~L} \mathrm{~kg}^{-1}$, respectively. The distribution coefficients relative to the soil organic carbon $\left(\mathrm{K}_{\mathrm{oc}}\right)$ were $166 \mathrm{~L} \mathrm{~kg}^{-1}$ on no-till and $126 \mathrm{~L} \mathrm{~kg}^{-1}$ on conventional tillage, showing that the herbicide was sorbed in a greater extent by the organic matter from the no-till system.
\end{abstract}

Index terms: weeds, soil management, sorption, leaching.

\section{Introdução}

O manejo do solo afeta a atividade dos herbicidas residuais e influi, desta forma, na eficácia de controle

\footnotetext{
(1) Aceito para publicação em 2 de agosto de 2002.

(2) Universidade Federal do Rio Grande do Sul (UFRGS), Instituto de Química, Av. Bento Gonçalves, 9500, CEP 91501-970 Porto Alegre, RS. Bolsista da Fapergs.

E-mail: mvwferri@bol.com.br

(3) UFRGS, Fac. de Agronomia, Dep. de Plantas de Lavoura, Caixa Postal 776, CEP 91540-000 Porto Alegre, RS. E-mail: vidal@if.ufrgs.br

(4) UFRGS, Fac. de Agronomia, Dep. de Solos. E-mail: julianag@cpovo.net

(5)UFRGS, Instituto de Química. E-mail: dpdick@iq.ufrgs.br rfds@iq.ufrgs.br
}

das plantas daninhas, na persistência e no risco de contaminação ambiental (Levanon et al., 1993; Weed et al., 1995). A atividade dos herbicidas residuais pode variar em razão do tipo e conteúdo de argila, do teor de matéria orgânica e da umidade do solo (Walker et al., 1992). Isto ocorre porque esses fatores afetam a sorção, a lixiviação e a degradação biológica, as quais regulam a concentração, a mobilidade e a persistência desses compostos no solo (Walker et al., 1992; Mueller et al., 1999).

A intensidade com que o manejo afeta a atividade dos herbicidas residuais depende dos efeitos sobre o conteúdo e infiltração de água e sobre o teor da matéria orgânica do solo. A infiltração de água promove a lixiviação, enquanto a matéria orgânica favorece a sorção dos herbicidas (Walker et al., 1992; Flury, 
1996). A semeadura direta pode incrementar a infiltração de água no solo, quando comparada ao preparo convencional, e favorecer o transporte de herbicidas e outros agroquímicos por lixiviação (Addiscott \& Dexter, 1994). A manutenção da estabilidade da estrutura, aliada à macroporosidade oriunda da atividade de raízes e organismos componentes da mesofauna, normalmente elevam a infiltração de água nesse sistema de preparo do solo. A macroporosidade pode favorecer o fluxo preferencial e permitir a lixiviação de herbicidas (Edwards et al., 1993; Sigua et al., 1995; Shipitalo et al., 2000). A lixiviação promove o transporte dos herbicidas no perfil do solo para além do alcance das raízes das plantas daninhas e pode reduzir a eficácia de controle pelos herbicidas residuais (Weed et al., 1995).

Além dos possíveis efeitos sobre a infiltração de água e a consequiente lixiviação de herbicidas, a semeadura direta incrementa o teor superficial de matéria orgânica e favorece a sorção desses compostos no solo (Levanon et al., 1993; Flury, 1996). A sorção é um importante mecanismo de redução da atividade de herbicidas residuais, pois controla o equilíbrio entre a concentração do composto em solução e a quantidade sorvida aos colóides orgânicos e minerais do solo. Conseqüentemente, esse processo regula a absorção dos herbicidas pelas raízes das plantas daninhas (Walker et al., 1992; Herwig et al., 2001).

Este trabalho teve por objetivo avaliar a eficácia de controle de plantas daninhas, a lixiviação e a sorção do herbicida acetochlor em relação ao tipo de manejo, atributos físicos e características da matéria orgânica do solo submetido à semeadura direta e ao preparo convencional.

\section{Material e Métodos}

O controle das plantas daninhas foi avaliado em experimento de campo, no ano agrícola de 1999/2000, na Estação Experimental Agronômica da Universidade Federal do Rio Grande do Sul (EEA/UFRGS), localizada no Município de Eldorado do Sul, RS. O solo utilizado é classificado como Argissolo Vermelho distrófico típico. Ambas as áreas foram cultivadas com aveia-preta e soja nos últimos sete anos, uma manejada sob semeadura direta e outra com preparo convencional (aração seguida de gradagem).

$\mathrm{O}$ delineamento experimental utilizado foi em blocos casualizados com quatro repetições, com tratamentos distribuídos em parcelas subsubdivididas. As parcelas principais mediram 10x16 m. As unidades experimentais mediram $2 \times 4 \mathrm{~m}$. Nas parcelas principais encontravam-se os preparos do solo (semeadura direta e convencional); nas subparcelas, as doses do acetochlor $(0,1.680,2.520$, $3.360 \mathrm{e} 4.200 \mathrm{~g} \mathrm{ha}^{-1}$ ), e nas subsubparcelas, as épocas de avaliação de controle das plantas daninhas $(20 \mathrm{e}$ 40 dias após aplicação do acetochlor (DAT)). O controle das plantas daninhas foi avaliado visualmente atribuindo-se notas que variaram de 0 a 100.

A pulverização do acetochlor (2-cloro-N-(etoximetil)$\mathrm{N}$-(2-etil-6-metil-fenil) acetamida, 99,9\% de pureza), foi realizada com pulverizador costal pressurizado a $\mathrm{CO}_{2}$, a pressão de $200 \mathrm{kPa}$, bicos tipo leque 8.002 distanciados em $0,50 \mathrm{~m}$ na barra de $1,5 \mathrm{~m}$ e volume de calda de $200 \mathrm{~L} \mathrm{ha}^{-1}$. $\mathrm{Na}$ semeadura direta, a vegetação existente sobre a superfície do solo foi controlada com $1.080 \mathrm{~g} \mathrm{ha}^{-1}$ de glyphosate dois dias antes da aplicação dos tratamentos. As principais plantas daninhas presentes em ambas as áreas eram Digitaria sp. (milhã), Bidens pilosa L. (picão-preto), Sida spp. (guanxuma) e Brachiaria plantaginea (Link) Hitchc. (papuã).

A lixiviação do herbicida acetochlor foi avaliada nas profundidades de 0-4, 6-9, 11-14 e 16-19 cm e determinada por bioensaio utilizando-se o trigo (Triticum aestivum L.) como planta-teste. A percolação do acetochlor no solo foi incentivada mediante irrigação de $20 \mathrm{~mm}$ de água em toda a área experimental, 24 horas após aplicação do herbicida. Durante a condução do experimento foram realizadas irrigações de $20 \mathrm{~mm}$ aos 14, 28, 35 e 45 DAT em toda a área experimental. Aos seis DAT ocorreu precipitação pluvial de $22 \mathrm{~mm}$ na área experimental. O solo para avaliação da lixiviação foi coletado 24 horas após a irrigação, a partir da extração de colunas de $20 \mathrm{~cm}$ de solo com tubos de PVC de $50 \mathrm{~mm}$ de diâmetro. A coleta foi realizada na mesma parcela de avaliação da eficácia de controle das plantas daninhas, que recebeu a dose de acetochlor de $3.360 \mathrm{~g} \mathrm{ha}^{-1} \mathrm{de}$ ingrediente ativo. Em ambos os sistemas de preparo foram coletadas amostras de solo sem herbicida como testemunha. As amostras coletadas foram armazenadas a $3^{\circ} \mathrm{C}$ para posterior avaliação da lixiviação dos herbicidas via bioensaio. As colunas foram cortadas longitudinalmente na região terço-superior, o solo foi desestruturado e a semeadura de sementes pré-germinadas de trigo foi realizada no interior das colunas. As plantas desenvolveram-se em câmara de crescimento a $20^{\circ} \mathrm{C}$, fotoperíodo de 12 horas e umidade controlada. $\mathrm{O}$ acetochlor lixiviado foi avaliado aos 10 dias da emergência do trigo, considerando-se a porcentagem de redução de altura e de produção de matéria seca das plantas em relação à testemunha sem herbicida, em quatro profundidades. $\mathrm{O}$ delineamento experimental utilizado foi em blocos casualizados com três repetições, e os 
tratamentos distribuídos em parcelas subdivididas. Nas parcelas principais foram dispostos os preparos do solo: semeadura direta e preparo convencional, e nas subparcelas as profundidades de 0-4, 6-9, 11-14 e 16-19 cm.

A sorção do herbicida acetochlor foi realizada em amostras de solo coletadas na profundidade de $0-10 \mathrm{~cm}$ nas áreas de semeadura direta e preparo convencional, nas quais foram avaliados previamente a lixiviação e o controle de plantas daninhas. O solo foi peneirado e seco ao ar e à sombra. A isoterma de sorção foi obtida agitando-se 2 gramas de solo com $20 \mathrm{~mL}$ de solução contendo $5,10,15,20$, $30 \mathrm{e} 40 \mathrm{mg} \mathrm{L}^{-1}$ de acetochlor, durante 24 horas, à temperatura de $25^{\circ} \mathrm{C}$. Todas as concentrações foram avaliadas em duplicata. A força iônica foi ajustada para $0,01 \mathrm{~mol} \mathrm{~L}^{-1} \mathrm{com}$ solução de cloreto de cálcio $\left(\mathrm{CaCl}_{2}\right)$. Após a agitação, as amostras foram centrifugadas (4.000 rpm por 15 minutos), filtradas e os sobrenadantes armazenados a $3^{\circ} \mathrm{C}$. Foram realizadas medidas de $\mathrm{pH}$ das soluções antes e após a sorção do acetochlor no solo. Foram utilizadas, também, duas provas em branco: (1) acetochlor na concentração de $40 \mathrm{~mL} \mathrm{~L}^{-1}$, para verificar possível degradação do herbicida durante o procedimento de sorção e (2) solo em solução de $\mathrm{CaCl}_{2} 0,01 \mathrm{~mol} \mathrm{~L}^{-1}$ para monitorar possível extração de substâncias orgânicas com pico cromatográfico com tempo de retenção semelhante ao do acetochlor.

A concentração de acetochlor em solução após a sorção foi determinada por cromatografia líquida de alta performance HPLC, utilizando-se detector ultra-violeta e coluna de fase reversa RP-18 (250 $\mathrm{mm} \times 4,6 \mathrm{~mm})$. O comprimento de onda do detector foi de $220 \mathrm{~nm}$, a fase móvel foi metanol diluído em água, na proporção 70:30 (v/v), a taxa de fluxo foi de $0,8 \mathrm{~mL} \mathrm{~min}^{-1}$. Durante a injeção, as amostras foram filtradas em membranas com poros de $0,45 \mathrm{~mm}$ de diâmetro. Para cada amostra foram realizadas duas leituras cromatográficas, e a concentração de acetochlor foi obtida pela média aritmética dos valores. A diferença entre a concentração inicial e a de equilíbrio foi assumida como a quantidade de acetochlor sorvida no solo. Aos dados de quantidade sorvida ( $\mathrm{Q}_{\text {ads }}, \mathrm{mg} \mathrm{kg}^{-1}$ ) e concentração de equilíbrio $\left(\mathrm{C}_{\mathrm{eq}}, \mathrm{mg} \mathrm{L}^{-1}\right)$, foi aplicada a isoterma (1):

$\mathrm{Q}_{\mathrm{ads}}=\mathrm{a}+\mathrm{bC}_{\mathrm{eq}}$

em que a representa uma constante e $b$ representa o coeficiente de partição $\mathrm{K}_{\mathrm{d}}\left(\mathrm{L} \mathrm{kg}^{-1}\right)$ do acetochlor no solo. O coeficiente de partição em relação ao carbono orgânico do solo $\left(\mathrm{K}_{\mathrm{oc}}\right)$ foi obtido pela equação (2):

$\mathrm{K}_{\mathrm{oc}}\left(\mathrm{L} \mathrm{kg}^{-1}\right)=\left(\mathrm{K}_{\mathrm{d}} / \mathrm{C}\right) \times 100$

em que $\mathrm{C}$ é o teor de carbono orgânico do solo $\left(\mathrm{mg} \mathrm{g}^{-1}\right)$.

Foram caracterizadas a densidade, a macro, micro e porosidade total e a condutividade hidráulica saturada do solo, pelos métodos descritos no Manual de Métodos de Análise de Solo (Embrapa, 1999). O teor de carbono orgâ- nico total do solo foi determinado pelo método de WalkleyBlack (Tedesco et al., 1995). A matéria orgânica do solo (MOS) foi concentrada por tratamento com solução de HF 10\% (Schmidt et al., 1997) e a análise elementar da MOS foi determinada em analisador elementar Perkin Elmer 2400. Os teores de $\mathrm{C}, \mathrm{H}$ e $\mathrm{N}$ foram corrigidos para uma base livre de cinzas, e o teor de oxigênio foi calculado por diferença: $\mathrm{O}\left(\mathrm{mg} \mathrm{g}^{-1}\right)=1.000-(\mathrm{C}+\mathrm{H}+\mathrm{N})$. O teor de cinzas foi determinado por calcinação a $750^{\circ} \mathrm{C}$ durante quatro horas. Foram calculadas a relação $\mathrm{C} / \mathrm{N}$ e as razões atômicas $\mathrm{H} / \mathrm{C}$ e O/C. A área superficial específica (ASE) foi determinada em amostras de solo oriundas dos dois sistemas de preparo segundo método da adsorção de água (Quirk, 1955), empregando-se três repetições.

$\mathrm{Na}$ análise estatística, os dados de porcentagem de controle de plantas daninhas e de redução de altura e matéria seca das plantas de trigo em relação à testemunha sem herbicida, obtidas no bioensaio, sofreram transformação para arco seno $\sqrt{\mathrm{x} / 100}$, ao serem submetidos à análise de variância. Os efeitos quantitativos das doses do acetochlor foram avaliados por intermédio de análise de regressão, considerando-se modelo linear. A lixiviação de acetochlor, nas profundidades de solo estudadas, o teor de carbono orgânico, a ASE, bem como os valores relativos às características físicas dos solos nas diferentes profundidades, foram avaliados comparando-se as médias dos tratamentos pelo teste de Tukey $(\mathrm{P} \leq 0,05)$ após serem submetidos à análise de variância. A variação de sorção de acetochlor entre os sistemas de preparo foi avaliada submetendo-se os dados de $\mathrm{C}_{\mathrm{eq}} \mathrm{e} \mathrm{Q}_{\mathrm{ads}}$ à análise de variância, seguindo o modelo de experimento fatorial hierárquico. Na obtenção da equação da isoterma foi avaliada a correlação entre a concentração de equilíbrio $\left(\mathrm{C}_{\mathrm{eq}}\right)$ e a quantidade sorvida $\left(Q_{\text {ads }}\right)$ verificando-se o nível de significância do coeficiente de correlação (r). Os coeficientes de partição $K_{d}$ e $K_{o c}$ nos dois sistemas de preparo foram comparados verificandose o nível de significância em relação à diferença entre duas médias de tratamento pelo teste $\mathrm{t}$.

\section{Resultados e Discussão}

Os dados da Tabela 1 mostram diferenças nos atributos determinados no solo em função do manejo. Em ambos os sistemas de manejo, a densidade do solo aumentou com a profundidade, porém observaram-se maior densidade e microporosidade na profundidade de 0-5 cm e menor densidade na profundidade de $15-20 \mathrm{~cm}$ na semeadura direta. A porosidade total e a macroporosidade foram superiores no preparo convencional na profundidade de $0-5 \mathrm{~cm}$ e na semeadura direta, entre $15-20 \mathrm{~cm}$. A condutividade 
hidráulica saturada foi maior na profundidade de 0-10 cm no solo com preparo convencional e de $10-20 \mathrm{~cm}$ na semeadura direta. $\mathrm{O}$ preparo convencional do solo, por ter elevado a porosidade total e a macroporosidade na profundidade de $0-5 \mathrm{~cm}$ pode ter favorecido a condutividade hidráulica saturada, na profundidade de $0-10 \mathrm{~cm}$. A ausência de preparo e a conseqüente manutenção da estabilidade na estrutura pode ter favorecido a condutividade hidráulica saturada a $10-20 \mathrm{~cm}$ na semeadura direta.

O teor de carbono orgânico total na profundidade de $0-10 \mathrm{~cm}$ foi superior na semeadura direta em relação ao preparo convencional. A semeadura direta pode promover aumento da densidade e do teor de carbono orgânico nas camadas superficiais do solo, enquanto o preparo convencional tende a aumentar a macroporosidade e reduzir a densidade do solo (Rhoton et al., 1993; Crawford, 1994; Shipitalo et al., 2000).

O controle de plantas daninhas com o acetochlor variou de acordo com o preparo do solo, dose do herbicida e época de avaliação. Aos 20 DAT, apenas na dose aplicada de $1.680 \mathrm{~g} \mathrm{ha}^{-1}$ foi observada diferença de eficácia no controle de plantas daninhas entre os dois sistemas de preparo. Aos 40 DAT, o acetochlor apresentou controle das plantas daninhas inferior a $45 \%$ na semeadura direta, mesmo quando aplicado na dose de $4.200 \mathrm{~g} \mathrm{ha}^{-1}$, ao passo que no solo sob preparo convencional observou-se $80 \%$ e $87 \%$ de controle com as doses de 3.360 e $4.200 \mathrm{~g} \mathrm{ha}^{-1}$, respectivamente (Figura 1).

A produtividade das culturas pode ser reduzida dependendo da intensidade, época e duração da interferência proporcionada pela presença das plantas daninhas. Desta forma, considerando $85 \%$ como o controle mínimo necessário para que as culturas expressem seu potencial produtivo, e que o período total de prevenção da interferência em culturas anuais como milho e soja estende-se até 40 a 50 dias de seu ciclo (Hall et al., 1992; Fleck \& Candemil, 1995), somente as doses de 3.360 e $4.200 \mathrm{~g} \mathrm{ha}^{-1}$ de acetochlor no solo com preparo convencional proporcionaram controle satisfatório até 40 DAT (Figura 1). Esse resultado sugere a necessidade de uso de doses superiores às normalmente utilizadas, notadamente na semeadura direta, para controle das plantas daninhas com acetochlor.

No presente estudo, o incremento no teor superficial de carbono orgânico e na condutividade hidráulica saturada na profundidade de $10-20 \mathrm{~cm}$ (Tabela 1), e a presença da palha sobre a superfície do solo $\left(5 \mathrm{t} \mathrm{ha}^{-1}\right)$, observados na semeadura direta, podem ter afetado a atividade do herbicida acetochlor e reduzido sua eficácia de controle das plantas daninhas nesse sistema de preparo do solo. Variações na atividade de herbicidas cloroacetamidas ocorrem em razão de diferenças no teor de matéria orgânica, estrutura, cobertura do solo com palha e cátions presentes no complexo de troca dos solos (Pusino et al., 1993; Burgos \& Talbert, 1996).

Em relação à lixiviação do herbicida acetochlor no solo, os dados de redução de altura de plantas e de matéria seca da parte aérea de trigo em relação à testemunha sem herbicida demonstraram que a eficácia do composto foi superior no solo com preparo convencional quando comparado à semeadura direta, nas profundidades de 0-4 e 6-9 cm (Tabela 2). A menor eficácia do acetochlor na superfície do solo sob semeadura direta pode decorrer da sorção do herbicida ao solo ou à palha. A presença de resíduos vegetais

Tabela 1. Densidade, macroporosidade, microporosidade, e porosidade total, carbono orgânico total e condutividade hidráulica saturada, em diferentes profundidades de coleta em solo sob semeadura direta (SD) e preparo convencional (PC). Eldorado do Sul, RS, 1999/2000(1).

\begin{tabular}{|c|c|c|c|c|c|c|c|c|c|c|c|c|}
\hline \multirow[t]{2}{*}{$\begin{array}{l}\text { Profundidade } \\
(\mathrm{cm})\end{array}$} & \multicolumn{2}{|c|}{$\begin{array}{l}\text { Densidade } \\
\left(\mathrm{g} \mathrm{cm}^{-3}\right)\end{array}$} & \multicolumn{2}{|c|}{$\begin{array}{l}\text { Macroporosidade } \\
\qquad\left(\mathrm{m}^{3} \mathrm{~m}^{-3}\right)\end{array}$} & \multicolumn{2}{|c|}{$\begin{array}{l}\text { Microporosidade } \\
\left(\mathrm{m}^{3} \mathrm{~m}^{-3}\right)\end{array}$} & \multicolumn{2}{|c|}{$\begin{array}{l}\text { Porosidade } \\
\text { total }\left(\mathrm{m}^{3} \mathrm{~m}^{-3}\right)\end{array}$} & \multicolumn{2}{|c|}{$\begin{array}{l}\text { C orgânico } \\
\text { total }\left(\mathrm{mg} \mathrm{g}^{-1}\right)\end{array}$} & \multicolumn{2}{|c|}{$\begin{array}{l}\text { Condutividade } \\
\text { hidráulica }\left(\mathrm{cm} \mathrm{h}^{-1}\right)\end{array}$} \\
\hline & SD & $\mathrm{PC}$ & SD & $\mathrm{PC}$ & SD & $\mathrm{PC}$ & SD & $\mathrm{PC}$ & SD & $\mathrm{PC}$ & $\mathrm{SD}^{(2)}$ & $\mathrm{PC}^{(2)}$ \\
\hline $0-5$ & $1,64 \mathrm{Ca}$ & $1,34 \mathrm{Db}$ & $0,193 \mathrm{Ab}$ & 0,279Aa & $0,170 \mathrm{BCa}$ & $0,138 \mathrm{Db}$ & $0,363 \mathrm{ABb}$ & $0,415 \mathrm{Aa}$ & $15,1 \mathrm{Aa}$ & $12,8 \mathrm{Ab}$ & & \\
\hline $5-10$ & $1,66 \mathrm{BCa}$ & $1,59 \mathrm{Ca}$ & $0,217 \mathrm{Aa}$ & $0,204 \mathrm{Ba}$ & $0,164 \mathrm{Ca}$ & $0,159 \mathrm{Ca}$ & 0,381Aa & $0,363 \mathrm{Ba}$ & $11,8 \mathrm{Ba}$ & $10,4 \mathrm{Bb}$ & $15,8 \mathrm{Ab}$ & $24,1 \mathrm{Aa}$ \\
\hline $10-15$ & $1,72 \mathrm{ABa}$ & $1,71 \mathrm{Ba}$ & $0,177 \mathrm{BCa}$ & $0,183 \mathrm{Ca}$ & $0,182 \mathrm{Aa}$ & $0,171 \mathrm{Ba}$ & $0,359 \mathrm{Ba}$ & $0,354 \mathrm{Ba}$ & $8,8 \mathrm{Cb}$ & $12,2 \mathrm{Ba}$ & & \\
\hline $15-20$ & $1,76 \mathrm{Ab}$ & $1,82 \mathrm{Aa}$ & $0,159 \mathrm{Ca}$ & $0,130 \mathrm{Db}$ & $0,178 \mathrm{ABa}$ & $0,181 \mathrm{Aa}$ & $0,337 \mathrm{Ca}$ & $0,314 \mathrm{Cb}$ & $8,5 \mathrm{Ca}$ & $8,6 \mathrm{Ca}$ & $11,1 \mathrm{Ba}$ & $5,1 \mathrm{Bb}$ \\
\hline $\mathrm{CV}(\%)$ & \multicolumn{2}{|c|}{1,9} & \multicolumn{2}{|c|}{5,0} & \multicolumn{2}{|c|}{2,1} & \multicolumn{2}{|c|}{2,5} & \multicolumn{2}{|c|}{18,0} & \multicolumn{2}{|c|}{4,3} \\
\hline
\end{tabular}

${ }^{(1)}$ Médias seguidas pela mesma letra, maiúscula nas colunas e minúscula nas linhas, não diferem entre si pelo teste de Tukey a 5\% de probabilidade. ${ }^{(2)}$ Condutividade hidráulica saturada, profundidades de $0-10$ e $10-20 \mathrm{~cm}$. 
sobre a superfície do solo pode influir na atividade dos herbicidas cloroacetamidas, como acetochlor, alachlor e metolachlor (Banks \& Robinson, 1986). A maior concentração de acetochlor na superfície do solo com preparo convencional explica a maior eficácia de controle de plantas daninhas observado nesse sistema de preparo do solo (Figura 1).

A redução de matéria seca da parte aérea de trigo demonstrou também que a concentração do acetochlor foi maior na profundidade de $16-19 \mathrm{~cm}$ na semeadura direta em comparação ao preparo convencional (Tabela 2). Porém, na profundidade de 0-4 cm houve maior redução da matéria seca no solo com preparo convencional. Tais resultados sugerem que o herbicida acetochlor apresentou maior lixiviação na semeadura direta e indicam que o menor controle de plantas daninhas observado na semeadura direta seja decorrente, ao menos em parte, da maior mobilidade do herbicida nesse sistema de manejo do solo.

A semeadura direta, comparada ao preparo convencional, apresentou maior condutividade hidráulica saturada na profundidade de $10-20 \mathrm{~cm}$ (Tabela 1). Esse atributo pode ser considerado como indicativo do tamanho, estabilidade e continuidade do sistema poroso, os quais determinam as taxas de movimento e infiltração de água no solo (Crawford, 1994; Shipitalo et al., 2000). A maior condutividade hidráulica saturada na profundidade de $10-20 \mathrm{~cm}$, a menor

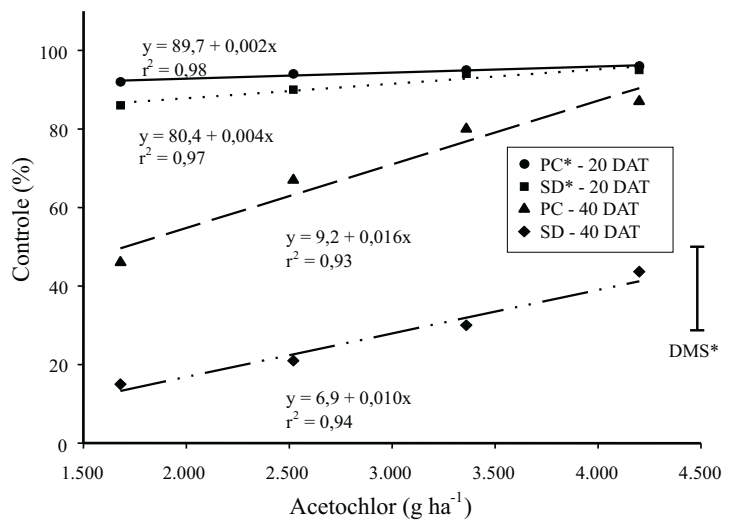

Figura 1. Controle de plantas daninhas em solo sob semeadura direta (SD) e preparo convencional (PC) aos 20 e 40 dias após aplicação do herbicida acetochlor. Eldorado do Sul, RS, 1999/2000. *Significativo a 5\% de probabilidade pelo teste de F. densidade e a maior macroporosidade na profundidade de $15-20 \mathrm{~cm}$ na semeadura direta podem ter favorecido a lixiviação de acetochlor e, consequientemente, maior redução de matéria seca de trigo nessa profundidade na semeadura direta (Tabela 2).

Além do controle de plantas daninhas e da lixiviação, a sorção de herbicida acetochlor também variou entre a semeadura direta e o preparo convencional, cujas diferenças entre as formas de preparo se manifestaram a partir da concentração de equilíbrio de $20 \mathrm{mg} \mathrm{L}^{-1}$ (Figura 2). Equações lineares foram coerentes para correlacionar a sorção do acetochlor em ambas as formas de preparo do solo (Figura 2). As provas em branco mostraram que não houve degradação do herbicida durante a realização das isotermas e tampouco houve interferência de compostos coextraídos na determinação cromatográfica de acetochlor.

Os parâmetros $\mathrm{K}_{\mathrm{d}}$ e $\mathrm{K}_{\mathrm{oc}}$, indicadores da sorção de herbicida acetochlor pelo solo, e em razão do teor de carbono orgânico, foram, respectivamente, de $2,75 \mathrm{~L} \mathrm{~kg}^{-1} \mathrm{e} 166 \mathrm{~L} \mathrm{~kg}^{-1}$ no solo sob semeadura direta e $1,67 \mathrm{~L} \mathrm{~kg}^{-1}$ e $126 \mathrm{~L} \mathrm{~kg}^{-1}$ no solo com preparo convencional (Tabela 3). Os valores de $\mathrm{K}_{\mathrm{d}}$ e $\mathrm{K}_{\mathrm{oc}}$ obtidos neste trabalho estão dentro dos limites normalmente apresentados por outros herbicidas cloroacetamidas (Pusino et al., 1993; Yen et al., 1994). Não se observaram diferenças na área superficial específica entre o solo sob semeadura direta e sob preparo convencional (Tabela 3), e, portanto, a maior sorção do

Tabela 2. Porcentagem de redução de altura de plantas e de matéria seca da parte aérea de trigo, em bioensaio de lixiviação um dia após a aplicação do herbicida acetochlor em solo sob semeadura direta (SD) e preparo convencional (PC) em diferentes profundidades. Porto Alegre, RS, $1999 / 2000^{(1)}$.

\begin{tabular}{|c|c|c|c|c|}
\hline \multirow[t]{2}{*}{$\begin{array}{l}\text { Profundidade } \\
(\mathrm{cm})\end{array}$} & \multicolumn{2}{|c|}{ Altura de plantas } & \multicolumn{2}{|c|}{$\begin{array}{c}\text { Matéria seca } \\
\text { da parte aérea }\end{array}$} \\
\hline & SD & $\mathrm{PC}$ & SD & $\mathrm{PC}$ \\
\hline $0-4$ & $55 \mathrm{Aa}$ & $80 \mathrm{Ab}$ & $40 \mathrm{Aa}$ & $69 \mathrm{Ab}$ \\
\hline $6-9$ & $28 \mathrm{Ba}$ & $41 \mathrm{Bb}$ & $37 \mathrm{Aa}$ & $25 \mathrm{Ba}$ \\
\hline $11-15$ & $14 \mathrm{Ca}$ & $13 \mathrm{Ca}$ & $28 \mathrm{Aa}$ & $12 \mathrm{BCa}$ \\
\hline $16-19$ & $10 \mathrm{Ca}$ & $7 \mathrm{Ca}$ & $26 \mathrm{Aa}$ & $6 \mathrm{Cb}$ \\
\hline CV (Erro A) (\%) & \multicolumn{2}{|c|}{9,5} & \multicolumn{2}{|c|}{14,2} \\
\hline $\mathrm{CV}$ (Erro B) $(\%)$ & \multicolumn{2}{|c|}{17,5} & \multicolumn{2}{|c|}{26,4} \\
\hline
\end{tabular}

(1)Médias seguidas pela mesma letra, maiúscula nas colunas e minúscula nas linhas, não diferem significativamente pelo teste de Tukey a 5\% de probabilidade. 


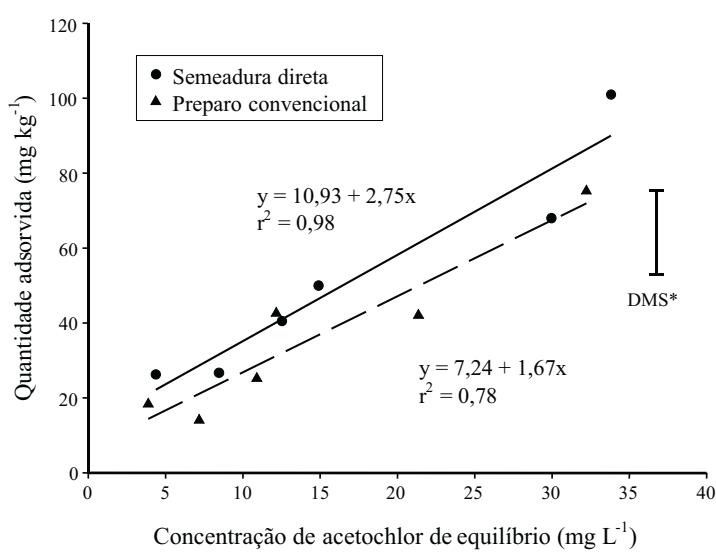

Figura 2. Isoterma de sorção do herbicida acetochlor em solo sob semeadura direta e preparo convencional. Porto Alegre, RS, 1999/2000. *DMS: diferença mínima significativa $(\mathrm{P} \leq 0,05)$.

Tabela 3. Coeficientes de partição do herbicida acetochlor no solo $\left(\mathrm{K}_{\mathrm{d}}\right)$, em relação ao carbono orgânico $\left(\mathrm{K}_{\mathrm{oc}}\right)$ e coeficiente de correlação (r) das regressões da Figura 2, carbono orgânico total e área superficial específica (ASE) em solo sob semeadura direta e preparo convencional. Porto Alegre, RS, 1999/2000.

\begin{tabular}{|c|c|c|c|c|c|}
\hline $\begin{array}{l}\text { Preparo } \\
\text { do solo }\end{array}$ & $\mathrm{K}_{\mathrm{d}}$ & $\begin{array}{c}\mathrm{K}_{\mathrm{oc}} \\
\left(\mathrm{L} \mathrm{kg}^{-1}\right)\end{array}$ & $\begin{array}{c}r \\
-\end{array}$ & $\begin{array}{c}C \text { orgânico }^{(1)} \\
\left(\mathrm{mg} \mathrm{g}^{-1}\right)\end{array}$ & $\begin{array}{c}\mathrm{ASE} \\
\left(\mathrm{m}^{2} \mathrm{~g}^{-1}\right)\end{array}$ \\
\hline Sem. direta & $2,75 \mathrm{a}^{(2)}$ & $166 a^{(2)}$ & $0,99 * *$ & $16,6 \mathrm{a}^{(3)}$ & $31,1 \mathrm{a}^{(3)}$ \\
\hline Convencional & $1,67 \mathrm{~b}$ & $126 \mathrm{~b}$ & $0,88^{*}$ & $13,3 b$ & $28,6 \mathrm{a}$ \\
\hline $\mathrm{CV}(\%)$ & & & & 2,1 & 13,1 \\
\hline
\end{tabular}

${ }^{(1)}$ Profundidade do solo de $0-10 \mathrm{~cm} .{ }^{(2)}$ Significativo a $7 \%$ de probabilidade pelo teste t. ${ }^{(3)}$ Médias seguidas pela mesma letra, na coluna, não diferem entre si pelo teste de Tukey a $5 \%$ de probabilidade. $* \mathrm{e}^{* * \text { Significativo a }}$ $5 \%$ e a $1 \%$ de probabilidade, respectivamente.

acetochlor na semeadura direta decorre do maior teor de carbono orgânico observado na profundidade de 0-10 cm neste sistema de preparo do solo.

A elevada capacidade da matéria orgânica em sorver herbicidas afeta a atividade biológica e a mobilidade destes compostos no solo. A sorção exerce papel determinante na atividade e, conseqüentemente, na eficácia de controle das plantas daninhas por herbicidas residuais (Willian et al., 1997).

Os valores obtidos de $\mathrm{K}_{\mathrm{oc}}$ (Tabela 3 ) mostram que a maior capacidade de retenção de acetochlor na semeadura direta não está apenas associada ao maior teor de carbono orgânico, porém às características da matéria orgânica. A composição elementar e as razões $\mathrm{H} / \mathrm{C}$ e $\mathrm{O} / \mathrm{C}$ da matéria orgânica foram similares em ambas as formas de preparo do solo (Tabela 4).
Tabela 4. Composição elementar (base livre de cinzas), razões atômicas e relação $\mathrm{C} / \mathrm{N}$ de matéria orgânica de solo sob semeadura direta e preparo convencional. Porto Alegre, RS, 1999/2000.

\begin{tabular}{|c|c|c|c|c|c|c|c|}
\hline \multirow[t]{2}{*}{$\begin{array}{l}\text { Preparo } \\
\text { do solo }\end{array}$} & \multicolumn{4}{|c|}{ Composição elementar } & \multicolumn{2}{|c|}{$\begin{array}{c}\text { Razões } \\
\text { atômicas }\end{array}$} & \multirow[t]{2}{*}{$\begin{array}{c}\text { Relação } \\
\text { C/N }\end{array}$} \\
\hline & $\mathrm{C}$ & $\mathrm{H}$ & $\mathrm{O}$ & $\mathrm{N}$ & $\mathrm{H} / \mathrm{C}$ & $\mathrm{O} / \mathrm{C}$ & \\
\hline & \multicolumn{6}{|c|}{---- $\left(\mathrm{mg} \mathrm{g}^{-1}\right)$} & \\
\hline Sem. direta & 479 & 54 & 430 & 37 & 1,4 & 0,7 & 14,9 \\
\hline Convencional & 467 & 47 & 448 & 39 & 1,2 & 0,7 & 14,1 \\
\hline
\end{tabular}

Tal resultado indica que o valor superior de $\mathrm{K}_{\mathrm{oc}}$ verificado na semeadura direta não está associado às características químicas da matéria orgânica. Alterações nas características estruturais e morfológicas da matéria orgânica, tais como razão C-aromático/ C-alifático, caráter hidrofóbico, tamanho de partícula, conformação da molécula (Almendros, 1997; Martin-Neto et al., 2001) e tipo e abundância de cátions trocáveis (Herwig et al., 2001), podem estar relacionadas às diferenças nos valores de $\mathrm{K}_{\mathrm{oc}}$ observados no presente estudo.

\section{Conclusões}

1. Em solos do tipo Argissolo Vermelho o acetochlor apresenta menor eficácia de controle de plantas daninhas na semeadura direta, comparada ao preparo convencional, em razão da maior lixiviação e maior sorção do herbicida verificadas nesse sistema.

2. A semeadura direta reduz a atividade do acetochlor em relação ao preparo convencional.

\section{Referências}

ADDISCOTT, T. M.; DEXTER, A. R. Tillage and crop residue management effects on losses of chemicals from soils. Soil and Tillage Research, Amsterdam, v. 30, n. 1, p. 125-168, 1994.

ALMENDROS, G. Sorptive interactions of pesticides in soil treated with modified humic acids. European Journal of Soil Science, Oxford, v. 46, n. 2, p. 287-301, 1997.

BANKS, A. P.; ROBINSON, E. L. Soil reception and activity of acetochlor, alachlor, and metolachlor as affected by wheat (Triticum aestivum) straw and irrigation. Weed Science, Champaign, v. 34, n. 4, p. 607-611, 1986.

BURGOS, N. R.; TALBERT, R. E. Weed control and sweet corn (Zea mays var. rugosa) response in a no-till 
system with cover crops. Weed Science, Champaign, v. 44, n. 2, p. 355-361, 1996.

CRAWFORD, J. W. The relationship between structure and the hydraulic conductivity of soil. European Journal of Soil Science, Madison, v. 45, n. 2, p. 493-502, 1994.

EDWARDS, W. M.; SHIPITALO, M. J.; OWENS, L. B.; DICK, W. A. Factors affecting preferential flow of water and atrazine through earthworm burrows under continuous no-till corn. Journal of Environmental Quality, Madison, v. 22, n. 2, p. 453-457, 1993.

EMBRAPA. Serviço Nacional de Pesquisa de Solos (Rio de Janeiro, RJ). Sistema brasileiro de classificação de solos. Rio de Janeiro, 1999. 412 p.

FLECK, N. G.; CANDEMIL, C. R. G. Interferência de plantas daninhas na cultura da soja (Glycine $\max (\mathrm{L}$.) Merrill). Ciência Rural, Santa Maria, v. 25, n. 1, p. 2732, 1995.

FLURY, M. Experimental evidence of transport of pesticides through field soils: a review. Journal of Environmental Quality, Madison, v. 25, n. 1, p. 25-45, 1996.

HALL, R. M.; CLARENCE, J. S.; ANDERSON, G. W. The critical period of weed control in grain corn (Zea mays). Weed Science, Champaign, v. 40, n. 3, p. 441-447, 1992.

HERWIG, U.; KLUMPP, E.; NARRES, H. D.; SCHWUGER, M. J. Physicochemical interactions between atrazine and clay minerals. Applied Clay Science, Amsterdam, v. 18, p. 211-222, 2001.

LEVANON, D.; CODLING, E. E.; MEISSINGER, J. J.; STARR, J. L. Mobility of agrochemicals through soil from two tillage systems. Journal of Environmental Quality, Madison, v. 22, n. 1, p. 155-161, 1993.

MARTIN-NETO, L.; TRAGHETTA, D. G.; VAZ, C. M. P.; CRESTANA, S.; SPOSITO, G. On the interaction mechanisms of atrazine and hydroxyatrazine with humic acids. Journal of Environmental Quality, Madison, v. 30, n. 2, p. 520-525, 2001.

MUELLER, T. C.; SHAW, D. R.; WITT, W. W. Relative dissipation of acetochlor, alachlor, metolachlor, and SAN 582 from three surface soils. Weed Science, Lawrence, v. 13, n. 1, p. 341-346, 1999.

PUSINO, A.; LIU, W.; GESSA, C. Influence of organic matter and its clay complexes on adsorption on soil. Pesticide Science, London, v. 36, n. 1, p. 283-286, 1993.
QUIRK, J. P. Significance of surfaces areas calculated from water vapor sorption isotherms by use of BET equation. Soil Science, Madison, v. 80, n. 6, p. 423-430, 1955.

RHOTON, F. E.; BRUCE, R. R.; BUEHRING, N. W.; ELKINS, G. B.; LANGDALE, C. W.; TYLER, D. D. Chemical and physical characteristics of four soil types under conventional and no-tillage systems. Soil and Tillage Research, Amsterdam, v. 28, n. 1, p. 51-61, 1993.

SCHMIDT, W. W. I.; KNICKER, H.; HATCHER, P. G.; KÖGEL-KNABNER, I. Improvement of ${ }^{13} \mathrm{C}$ and ${ }^{15} \mathrm{~N}$ CPMAS NMR spectra of bulk soils, particle size fractions and organic material by treatment with $10 \%$ hydrofluoric acid. European Journal of Soil Science, Oxford, v. 48, n. 2, p. 319-328, 1997.

SHIPITALO, M. J.; DICK, W. A.; EDWARDS,W. M. Conservation tillage and macropore factors that affect water movement and the fate of chemicals. Soil and Tillage Research, Amsterdam, v. 53, n. 1, p. 167-183, 2000.

SIGUA, G. C.; ISENSEE, A. R.; SADEGHI, A. M. Influence of tillage, antecedent moisture, and rainfall timing on atrazine transport. Weed Science, Champaign, v. 43, n. 1, p. 134-139, 1995.

TEDESCO, M. J.; GIANELLO, C.; VOLKWEISS, S. J.; BISANI, C. A. Análises de solo, plantas e outros materiais. Porto Alegre: UFRGS, 1995. 173 p. (Boletim Técnico de Solos, 5).

WALKER, A.; MOON, Y.; WELCH, S. J. Influence of temperature, soil moisture and soil characteristics on the persistence of alachlor. Pesticide Science, London, v. 35, n. 1, p. 109-116, 1992.

WEED, D. A. J.; KANWAR, R. S.; STOLTENBERG, D. E.; PFEIFFER, R. L. Dissipation and distribution of herbicides in the soil profile. Journal of Environmental Quality, Madison, v. 24, n. 1, p. 68-79, 1995.

WILLIAN, T. W.; MUELLER, T. C.; HAYES, R. M.; SNIPES, C. E.; BRIDGES, D. C. Adsorption, dissipation and movement of fluometuron in three Southeastern United States soils. Weed Science, Lawrence, v. 45, n. 1, p. 183$189,1997$.

YEN, P. Y.; KOSKINEN, W. C.; SCHWEIZER, E. E. Dissipation of alachlor in four soils as influenced by degradation and sorption processes. Weed Science, Champaign, v. 42, n. 2, p. 233-240, 1994. 